University of Nebraska - Lincoln

DigitalCommons@University of Nebraska - Lincoln

2013

\title{
Gender differences in substance use treatment utilization in the year prior to deployment in Army service members
}

\author{
Nikki R. Wooten \\ University of South Carolina, nwooten@sc.edu \\ Beth A. Mohr \\ Brandeis University \\ Lena M. Lundgren \\ Boston University \\ Rachel Sayko Adams \\ Brandeis University \\ Elizabeth L. Merrick \\ Brandeis University \\ See next page for additional authors
}

Follow this and additional works at: https://digitalcommons.unl.edu/usarmyresearch

Wooten, Nikki R.; Mohr, Beth A.; Lundgren, Lena M.; Sayko Adams, Rachel; Merrick, Elizabeth L.; Williams, Thomas V.; and Larson, Mary Jo, "Gender differences in substance use treatment utilization in the year prior to deployment in Army service members" (2013). US Army Research. 234.

https://digitalcommons.unl.edu/usarmyresearch/234

This Article is brought to you for free and open access by the U.S. Department of Defense at DigitalCommons@University of Nebraska - Lincoln. It has been accepted for inclusion in US Army Research by an authorized administrator of DigitalCommons@University of Nebraska - Lincoln. 


\section{Authors}

Nikki R. Wooten, Beth A. Mohr, Lena M. Lundgren, Rachel Sayko Adams, Elizabeth L. Merrick, Thomas V. Williams, and Mary Jo Larson 


\title{
Gender differences in substance use treatment utilization in the year prior to deployment in Army service members ${ }^{2}$
}

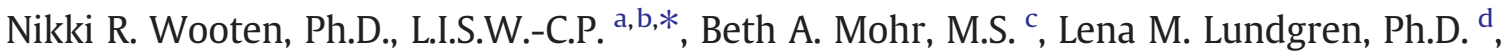 \\ Rachel Sayko Adams, Ph.D., M.P.H. ' ${ }^{\text {, }}$ Elizabeth L. Merrick, Ph.D., M.S.W. ${ }^{\text {c }}$, \\ Thomas V. Williams, Ph.D. ${ }^{\mathrm{e}}$, Mary Jo Larson, Ph.D., M.P.A. ${ }^{\mathrm{c}}$ \\ a University of South Carolina, College of Social Work, Columbia, SC \\ ${ }^{\mathrm{b}}$ Major(P), District of Columbia Army National Guard, Washington, DC \\ c Brandeis University, Institute for Behavioral Health, Heller School for Social Policy and Management, Waltham, MA \\ d Boston University, School of Social Work, Boston, MA \\ e Center for Healthcare Management Studies, TRICARE Management Activity, Department of Defense
}

\section{A R T I C L E I N F O}

\section{Article history:}

Received 12 December 2012

Received in revised form 24 February 2013

Accepted 4 April 2013

\section{Keywords:}

Army

Substance use treatment utilization

Substance use diagnosis

Military deployment

Propensity score model

Gelberg-Andersen behavioral model for

vulnerable populations

Gender disparities

Combat veterans

\begin{abstract}
A B S T R A C T
Although military men have heavier drinking patterns, military women experience equal or higher rates of dependence symptoms and similar rates of alcohol-related problems as men at lower levels of consumption. Thus, gender may be important for understanding substance use treatment (SUT) utilization before deployment. Military health system data were analyzed to examine gender differences in both substance use diagnosis (SUDX) and SUT in 152,447 Army service members returning from deployments in FY2010. Propensity score analysis of probability of SUDX indicated that women had lower odds (AOR: $0.91,95 \% \mathrm{CI}$ : 0.86-0.96) of military lifetime SUDX. After adjusting for lifetime SUDX using propensity score analysis, multivariate regression found women had substantially lower odds (AOR: $0.61 ; 95 \% \mathrm{CI}$ : 0.54-0.70) of using SUT the year prior to deployment. Findings suggest gender disparities in military-provided SUT and a need to consider whether military substance use assessment protocols are sensitive to gender differences.
\end{abstract}

(c) 2013 Elsevier Inc. All rights reserved.

\section{Introduction}

The physical and psychological impact of the Iraq and Afghanistan wars has increased concerns about substance use (SU), its effect on military health and readiness, and the need for substance use treatment (SUT) among Operations Enduring Freedom and Iraqi Freedom (OEF/OIF) veterans (Department of the Army, 2010, 2012; Hoge et al., 2004; Institute of Medicine, 2012; Petrakis, Rosenheck, \& Desai, 2011). Binge drinking and/or heavy alcohol use has been linked to military deployment in several studies (Federman, Bray, \& Kroutil, 2000; Jacobson et al., 2008; Ramchand et al., 2011); and combat exposure has been linked not only to heavy drinking, but also with increased cigarette

\footnotetext{
Dr. Wooten is a Major(P) in the District of Columbia Army National Guard, but did not conduct this study as a part of her official military duties. Authors report no conflicts of interest.

* Corresponding author. University of South Carolina, College of Social Work, 128 Thornwell Annex, Columbia, SC 29208.

E-mail address: nwooten@sc.edu (N.R. Wooten).
}

use and prescription opioid misuse (Adams, Larson, Corrigan, Horgan, \& Williams, 2012; Bray, Hourani, \& Williams, 2011; Jacobson et al., 2008; Shen, Arkes, \& Williams, 2012). In a recent study of OEF/OIF veterans, $30.2 \%$ of men and $16.3 \%$ of women screened positive for hazardous drinking, and younger age was associated with hazardous drinking in both men and women (Cobb Scott et al., 2012). In 2010, the number of medical visits for acute alcohol diagnoses $(n=109,780)$ among active duty (AD) military members was 50\% higher than in 2001 (i.e., before OEF/OIF), and accounted for more than a three-fold increase in the number of hospital bed days during the same period (Armed Forces Health Surveillance Center, 2011a). Between 2001 and 2010, 190,302 AD military members had at least one medical visit involving an acute alcohol diagnosis (Armed Forces Health Surveillance Center, 2011a). In the Millennium Cohort Study (Jacobson et al., 2008), $47.3 \%$ ( $n=6743$ ) of service members who did not deploy to OEF/ OIF screened positive for a history of potential alcohol dependence at baseline. Despite these high rates of heavy alcohol use in the military, SUT rates are low among service members identified with SU problems (Hoge et al., 2004; Institute of Medicine, 2012), suggesting that SUT access and utilization in the military requires 
further inquiry. Although women's military and deployment roles have expanded significantly, much less is known about SU diagnosis (SUDX) among military women and their access to SUT.

Women's military roles are important to military readiness given that they serve in over $90 \%$ of military occupations; including aviation, transportation, military police, logistics, and health care (Manning \& Wight, 2000; Smith et al., 2007a). Women currently comprise $14.5 \%$ of $\mathrm{AD}$ forces (Armed Forces Health Surveillance Center, 2011b) and approximately $10 \%(n=154,548)$ of personnel deployed in OEF/OIF (Armed Forces Health Surveillance Center, 2012a). Compared to civilian women, military women in all age groups and Army women age 35 and under have higher rates of heavy drinking, and Army women age 45 and under have higher rates of binge drinking than their civilian peers (Bray et al., 2009). In the Iraq and Afghanistan wars, military women have deployment roles similar to men (Smith, Jacobson, et al., 2007) increasing their risk for combat exposure, life-threatening injuries, and deployment-related health problems (Street, Vogt, \& Dutra, 2009; Vogt et al., 2011). Although military men have heavier drinking patterns (Ames \& Cunradi, 2004; Jacobson et al., 2008), military women have equal or higher rates of dependence symptoms and experience similar rates of alcohol-related problems as men at lower levels of consumption (Brown, Bray, \& Hartzell, 2010). The Millennium Cohort Study also found a greater proportion of military women were heavy weekly drinkers (defined as more than 14 drinks weekly for men and more than 7 weekly for women) than men, and more military men were binge drinkers than women at baseline and at new-onset of problem drinking (Jacobson et al., 2008). These gender differences suggest a need to better understand military women's SU and SUT patterns. Given differences in SU patterns and dependence between men and women in civilian populations (K. T. Brady \& Randall, 1999; World Health Organization, 2005), gender may be an important factor to explore to better understand SUDX and treatment utilization prior to military deployment.

While gender differences have been found in a vast array of SU studies, including etiology, patterns, tolerance, disease progression, treatment access and outcomes (Ashley, Marsden, \& Brady, 2003; K. T. Brady \& Randall, 1999; T. M. Brady \& Ashley, 2005; Greenfield et al., 2007; Weisner \& Schmidt, 1992), little research has focused on gender differences in SUT use in military treatment facilities (MTFs). Current evidence from Veterans Health Administration (VHA) studies support the importance of gender in understanding SUT patterns in military personnel and veterans. Recent evidence indicated a decline in women veterans' alcohol treatment rates compared to their civilian peers from 1992 to 2003 (Wallace, Sheehan, \& Young-Xu, 2009). In 1992, women veterans' alcohol treatment rates were double those of their civilian peers in all age groups, but by 2003, women veteran's alcohol treatment rates were lower than their civilian peers (Wallace et al., 2009). In FY2008, 15,653 women veterans seen in the VHA were diagnosed with SUDX, but only 33\% $(n=5,099)$ received outpatient SUT (Oliva et al., 2012). Persian Gulf War women veterans (in all age groups) with SUDX were less likely to use VHA substance abuse services than men (Chatterjee et al., 2009). Other researchers have also found that women veterans seeking treatment in the VHA were less likely to receive VHA substance abuse treatment than men (Hoff \& Rosenheck, 1997; Maynard et al., 2004).

\subsection{Gender differences in the military context influencing substance use and treatment utilization}

Military personnel engage in occupations and specialties that are stressful, have high work demands, require frequent relocations and deployments, and the potential for multiple combat exposures. These work conditions increase the risk of SU, psychological problems, and life-threatening injuries (Armed Forces Health Surveillance Center, 2012b; Hoge et al., 2005; Seal et al., 2007; Smith, Zamorski, Smith, Riddle, LeardMann, Wells, et al., 2007b). Military men and women increasingly perform similar military and deployment duties, although differences still exist (Lindstrom et al., 2006; Smith et al., 2007a). Performing military duties similar to men may increase women's occupational stress and SU problems prior to deployment, physical and social availability of alcohol, and work-related drinking. Military women may also engage in similar off-duty risky behaviors as men, such as recreational SU, drinking to relax, or cope with stress and boredom. While both military men and women may be vulnerable or at high risk for SU problems because of young age (Ames \& Cunradi, 2004), a demanding work environment (Scioli, Otis, \& Keane, 2010), deployment, combat exposure, and posttraumatic stress disorder (PTSD; Jacobson et al., 2008), they may differ in how they experience and respond to military and deployment-related stressors because of the male-dominated culture of military organizations.

Military women's unique experiences may also increase their risk for SU in ways that differ from military men. Military women are more likely than men to experience military sexual trauma (22\% vs. $1 \%$ ) (Suris \& Lind, 2008) which is positively associated with SU, PTSD, and depression (Davis \& Wood, 1999; Skinner et al., 2000; Surís, Lind, Kashner, Borman, \& Petty, 2004). Among VHA treatment-seeking women, Davis and Wood (1999) found a high incidence of substance abuse among women veterans reporting military sexual trauma, with alcohol, marijuana, cocaine/crack, and opiates (except heroin) being the most common substances used. Additional stressors for military women include limited opportunities to earn badges and distinctions usually associated with combat specialties, direct and indirect challenges to their military rank and authority from male peers and subordinates, differential treatment, and systematic barriers impeding military career goals (Kelty, Kleykamp, \& Segal, 2010). Women health care specialists in the military are more likely than their male peers to report that receiving counseling would damage their military careers (Gibbons, Barnett, Hickling, Herbig-Wall, \& Watts, 2012). Pregnancy and motherhood may also be challenging for military women. Among 12,326 military women who deployed at least once and gave birth to their first child between January 2002 and June 2009 while on active duty, $30.9 \%(n=3,802)$ who deployed again before the end of December 2009 were diagnosed with one or more mental health diagnoses; and those women who deployed within six months postpartum had increased risk for post-deployment problems, including substance abuse, depression, and anxiety disorders (Armed Forces Health Surveillance Center, 2010). The similarities and differences in men and women's military and deployment experiences suggest a need to better understand gender differences in the rates at which military personnel are diagnosed with and access treatment for SU problems prior to deployment.

Although research on VHA SUT utilization is ample (Edens, Kasprow, Tsai, \& Rosenheck, 2011; Nazarian, Kimerling, \& Frayne, 2012; Oliva et al., 2012; Petrakis et al., 2011; Stecker, Fortney, Owen, McGovern, \& Williams, 2010), much less is known about active duty military personnel who receive care in Department of Defense (DoD) treatment facilities (Larson, Wooten, Adams, \& Merrick, 2012) and how treatment utilization differs by gender. To address this gap in research, the present study examined the presence of military lifetime SUDX and utilization of SUT services in the year prior to deployment in a cohort of recently redeployed (i.e., returned from deployment) Army service members. Research questions included: (1) What are the SUDX rates in Army men and women in their military lifetime? (2) What are the SUT utilization rates in the year prior to deployment? (3) Do the odds of receiving SUT differ for Army men and women after adjusting for the propensity to receive a military lifetime SUDX? Despite similarities in men and women's military roles, we hypothesized that military women's unique military experiences and SU patterns would result in them having lower rates of military lifetime 
SUDX and prior year SUT, as well as lower odds of receiving militaryprovided SUT compared to military men.

\subsection{The Gelberg-Andersen behavioral model for vulnerable populations}

The Gelberg-Andersen Behavioral Model for Vulnerable Populations (Gelberg, Andersen \& Leake, 2000), an expansion of the Andersen Behavioral Model of Health Services Utilization (Aday \& Andersen, 1974; Andersen, 1995), has utility in the examination of gender differences in military-provided SUT. In the Andersen Model, health is conceptualized broadly and has been used in civilian studies examining physical health services, addiction treatment, and mental health services utilization (Grella, Greenwell, Mays, \& Cochran, 2009; Stein et al., 2012; Tucker, Wenzel, Golinelli, Zhou, \& Green, 2011; Vijayaraghavan et al., 2012). The Andersen Model posits that predisposing, enabling, and need factors determine health behaviors and health services utilization. Characteristics such as age, race, and gender are "immutable" or predisposing. Because predisposing factors are not modified by changes in health policy, these attributes often "define target groups at greater risk of physical health problems [addiction, mental health problems], or poorer access and quality of care" (Aday \& Awe, 1997, p. 160). Prior research indicates that individual level differences in age, gender, and race/ethnicity are associated with SUT utilization (Harris, Bowe, Finney, \& Humphreys, 2009; Lundgren, Amodeo, Ferguson, \& Davis, 2001; Lundgren et al., 2013; Saum, Hiller, Leigey, Inciardi, \& Surratt, 2007).

The Gelberg-Andersen Model extends the Andersen Model (Andersen, 1995) by including vulnerability factors within the predisposing, need, and enabling domains. According to Gelberg, Andersen, and Leake (2000), these vulnerability factors were included in the model to better understand and account for challenges faced by vulnerable populations that may predict access to and use of behavioral health services. In this study, gender, due to differences in military and family roles, stigma, and discrimination, is hypothesized as a vulnerability factor to consider when examining health behaviors and treatment utilization. Hence, the primary focus is to examine gender differences in SUDX and SUT utilization in the military. First, traditional predisposing factors controlled for include age, marital status, and number of military dependents. Gender and race/ethnicity are controlled for as predisposing vulnerability factors. Prior (or multiple) deployments were identified as military-related predisposing vulnerability factors because they represent the frequent mobility and potential combat exposure associated with military service. Single parent status was also identified as a predisposing vulnerability factor. Traditional enabling factors included TRICARE eligibility and military rank. Short dwell time (less than 365 days between deployments) was identified as a military-related enabling vulnerability factor because it represents a competing military occupational need to deploy rather than receive SUT. Physical injury was identified as a traditional need factor. Need vulnerability factors included the propensity to receive a military lifetime SUDX because it represents a behavioral health risk associated with military service, and in this study, severity of need for SUT. Prior health behaviors included a history of mental health treatment utilization in the service members' military lifetime. In this study, we further hypothesized that military personnel are a vulnerable group due to their risk for substance misuse and potential need for SUT.

\section{Materials and methods}

To ensure protection of human subjects, this observational study was conducted with approval from Brandeis University's Committee for Protection of Human Subjects, Boston University's Institutional Review Board, and the DoD Human Research Protection Program (DoD Directive 3216.02) at the Office of the Assistant Secretary of Defense for Health Affairs/TRICARE Management Activity (OASD/
TMA). The TMA Privacy and Civil Liberties Office executed a Data Sharing Agreement for our use of protected health information to ensure compliance with DoD privacy and security regulations and the Health Insurance Portability and Accountability Act.

\subsection{Study cohort}

All active duty Army service members who returned from deployments in FY2010 were included in the study cohort. Army service members were identified by branch of military service and active duty status from the Defense Eligibility and Enrollment Service (DEERS) file. From the Contingency Tracking System (CTS), deployment records which had end dates during FY2010 were selected. Deployment records were cleaned by collapsing records which had overlapping time periods into one deployment. If there was more than one CTS record for a service member with a return date in FY2010, then the deployment with the first return date in FY2010 was identified as the "index deployment". The resulting cohort was comprised of 137,814 men and 14,633 women for a total of 152,477 cohort members with deployments ending in FY2010.

\subsection{Data sources}

In addition to DEERS and CTS records, the study obtained for each cohort member selected encounters and claims from the DoD Military Health System Data Repository (MDR). The DoD MDR is a worldwide health care management system comprised of direct care in MTFs, purchased care from civilian or other non-DoD facilities, and the DoD prescription drug transaction system. The behavioral health encounters and claims selected for these analyses came from the "mental health cube" data system, which summarizes all institutional, ambulatory, and prescription drug utilization for service members since FY2002. We analyzed person-level summary records from this longitudinal data set.

\subsection{Time periods}

The observation period for the dependent variables, "prior year", was a unique window constructed for each Army cohort member based on the start date of the index deployment, and was defined as the 365 days prior to the index deployment start date. The intention was to observe service members when they were not currently on a deployment, but were preparing for an upcoming deployment. For $8 \%$ of the cohort members (9\% of men, $6 \%$ of women), the prior year was less than 365 days because their index deployment occurred less than one year after a previous deployment (dates of occurrence not available). "Military lifetime" was used for some covariates and was defined as the period starting with the cohort member's first date of military health system (MHS) entitlement (or the beginning of FY2002 for service members whose entitlement began before FY2002) to the one year prior to the start date of the index deployment.

\subsection{Dependent variables}

For the first research question, the dependent variable was SUDX in military lifetime, defined by examining all diagnoses on all claims and encounters independent of position. To qualify as a SUDX, we required either one inpatient record or two outpatient claims/ encounters with a SUDX. SUDX codes covered a broad range of diagnoses inclusive of the Agency for Healthcare Research and Quality Clinical Classification codes for alcohol abuse, substance abuse, personal history of alcohol abuse or substance abuse codes, and additional ICD-9-CM codes for acute drug abuse, acute alcohol disease, chronic alcohol disease, opioid dependence, and sedative, hypnotic, and anxiolytic dependence. 
For the second and third research questions, the dependent variable was any SUT utilization measured as one or more inpatient (IP) admissions or outpatient (OP) encounters assigned a major diagnostic code (MDC) of 20 (alcohol/other drug use or alcohol/drug induced mental disorders). MDCs are based on principal ICD-9-CM diagnoses, grouping all codes into 25 mutually exclusive categories. While MDC 20 does not indicate type of care, the stay or encounter was characterized as services for alcohol and other drug disorder because of the diagnosis codes' principal position. We note that, based on diagnosis, the MDC 20 group captures detoxification and nonrehabilitation procedures as well as rehabilitation and therapeutic counseling. A secondary dependent variable for the third research question was the number of outpatient SUT ambulatory encounters among those who had at least one such encounter, again defined by encounters assigned MDC 20.

\subsection{Independent and covariate measures}

Gender was the primary independent variable in our analyses. A primary covariate was the propensity to receive a SUDX in military lifetime (used for research questions two and three only and described in statistical methods below). All demographic covariates were measured at the start date of the index deployment. The demographic measures included: Age in years, marital status (married, divorced/widowed, single), military rank (enlisted, commissioned officer, warrant officer), race/ethnicity (white, black, Asian, other), number of military dependents sponsored by the service member, and single parent status (yes/no) defined as single or divorced/widowed marital status and one or more military dependents. We included deployment history measures that may influence SUT, including any deployment prior to the index deployment (yes/no), and short dwell time (yes/no) defined as less than 365 days between the index deployment start date and the end of a prior deployment. We also adjusted for the variation in service members' length of military service by constructing a covariate for months of TRICARE eligibility, defined as the total months between first eligibility date and start date of the index deployment.

Finally, we constructed a measure of physical injury comorbidity for the prior year and mental health treatment utilization. Physical injury comorbidity was based on the Wounded, Ill, and Injured definitions in the MHS and was defined as amputations, burns, fractures, spinal injury, shrapnel, or blindness in the military lifetime. Mental health treatment utilization was defined as any admission or encounter for MDC 19 (mental diseases and disorders) in the military lifetime.

\subsection{Statistical analyses}

\subsubsection{Descriptive analyses}

Bivariate associations were tested using the chi-square test for independence (categorical variables) or the Wilcoxon rank-sum test (continuous variables). Due to the extreme right skew of the distribution of the number of outpatient SUT encounters, we recoded all values at or above 26 (95th percentile) to 26 before performing regression analyses.

\subsubsection{Propensity score model}

We wanted to adjust for gender differences in SUDX so that observed gender differences in SUT would not be confounded with gender differences in SUDX. Therefore, propensity score modeling was used to address this confounding (Schmidt, Tam, \& Larson, 2012; Suarez \& Faries, 2010). The propensity model was a logistic regression that regressed military lifetime SUDX on eight covariates (gender, age in years, race/ethnicity, marital status, military rank, TRICARE eligibility, prior deployment, short dwell time), each hypothesized to be associated with the severity of need for SUT and selected a priori based on prior research. To assess the association of gender with military lifetime SUDX (i.e., risk of need for SUT), we compared histograms of propensity scores for each gender (Fig. 1). Fig. 1 indicates that the distribution of risk of military lifetime SUDX is on average higher for Army men than women, although the overlap in risk is also apparent. Army men and women with the same military lifetime SUDX propensity scores are interpreted as having similar average risk of need for SUT. Hence, we included the service members' calculated propensity scores in the multivariate models of SUT in order to yield an unbiased estimate of the association between gender and SUT utilization the year prior to deployment.

\subsubsection{Multivariate regression models}

We examined two SUT utilization dependent variables, any SUT and number of SUT ambulatory encounters the year prior to deployment. Logistic regression was used to estimate the association of gender with SUT, and the adjusted odds ratios (AORs) and 95th

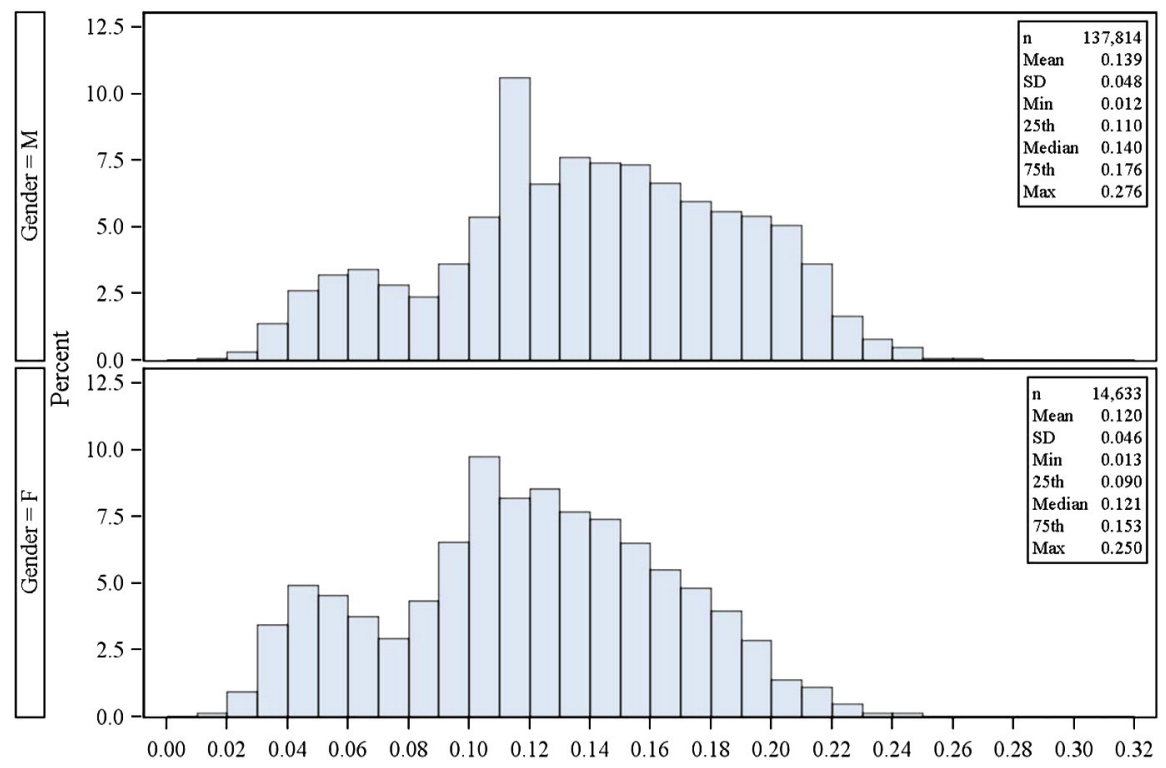

Fig. 1. Distribution of military lifetime substance use diagnosis propensity scores among army service members returning from deployment in FY2010, by Gender. 
percentile confidence intervals (CIs) were reported. Negative binomial regression was used to model the association of gender with the number of SUT encounters among service members with SUT encounters, and results were reported as risk ratios (RR) and 95\% Cls or percent change in risk (calculated as RR - 1, expressed as a percent). All independent variables discussed above were included in both models and to incorporate the individual's propensity score, we included the propensity scores in quintiles. Due to the large sample size of this study, we relied on both the magnitude of the statistic (e.g., odds ratio or relative risk) and $95 \% \mathrm{CI}$ instead of $p$-values to judge the importance of differences between gender groups. All statistical analyses were performed using SAS/STAT software ${ }^{\circledR} 9.2$ (SAS Institute Incorporated, 2008).

\section{Results}

Table 1 reports characteristics by gender. Mean age was 27.7 years for women and men, and women comprised $9.6 \%$ of the study cohort. Women were more likely than men to be black or other race/ethnicity, divorced/widowed or single, and a single parent. Regarding military characteristics, women were more likely to be military officers than men (16.4\% vs. $11.8 \%)$. Women were less likely than men $(49.7 \%$ vs. $62.9 \%)$ to have deployed prior to the index deployment; and thus women had fewer total months deployed. In their military lifetime, $26.2 \%$ of women had a mental health diagnosis, over twice the

Table 1

Prior year demographic and military characteristics of army men and women returning from deployment in FY2010.

\begin{tabular}{|c|c|c|}
\hline Demographic \& Military Characteristics & $\begin{array}{l}\text { Men } \\
n=137,814\end{array}$ & $\begin{array}{l}\text { Women } \\
n=14,633\end{array}$ \\
\hline Age $(\mathrm{yr})$, mean $(s d)$ & $27.7(7.2)$ & $27.7(7.1)$ \\
\hline \multicolumn{3}{|l|}{ Age (group), $n(\%)^{* * *}$} \\
\hline $18-24$ & $58,216(42.2)$ & $6,223(42.5)$ \\
\hline $25-29$ & $34,285(24.9)$ & $3,657(25)$ \\
\hline $30-39$ & $34,383(25)$ & $3,496(23.9)$ \\
\hline $40+$ & $10,930(8)$ & $1,257(8.6)$ \\
\hline \multicolumn{3}{|l|}{ Race/Ethnicity, $n(\%)^{* * *}$} \\
\hline White & $84,750(61.5)$ & $5,733(39.2)$ \\
\hline Black & $21,717(15.8)$ & $5,221(35.7)$ \\
\hline Asian & $23,589(17.1)$ & $2,422(16.6)$ \\
\hline Other & $7,758(5.6)$ & $1,257(8.6)$ \\
\hline \multicolumn{3}{|l|}{ Marital Status, $n(\%)^{* * *}$} \\
\hline Married & $84,598(61.4)$ & $6,856(46.9)$ \\
\hline Divorced/Widowed & $5,992(4.4)$ & $1,931(13.2)$ \\
\hline Single & $47,224(34.3)$ & $5,846(40.0)$ \\
\hline Single parent status, $n(\%)^{* * *}$ & $6,606(4.8)$ & $2,234(15.3)$ \\
\hline No. military dependents, mean (sd) & $1.54(1.6)$ & $0.90(1.3)$ \\
\hline \multicolumn{3}{|l|}{ Rank, group, $n(\%)^{* * *}$} \\
\hline Enlisted & $117,376(85.2)$ & $11,924(81.5)$ \\
\hline Officer & $16,206(11.8)$ & $2,401(16.4)$ \\
\hline Warrant Officer & $4,232(3.1)$ & $308(2.1)$ \\
\hline Months of TRICARE eligibility ${ }^{\mathrm{a}}$, mean $(s d)^{*}$ & $70.44(71)$ & $67.28(67)$ \\
\hline $\begin{array}{l}\text { FY2010 deployment length (months), } \\
\text { mean (sd) }\end{array}$ & $10.2(5.5)$ & $10.1(5.0)$ \\
\hline Prior deployment, $n(\%)^{* * *}$ & $86,774(62.9)$ & $7,278(49.7)$ \\
\hline $\begin{array}{l}\text { \# total months deployed, given prior } \\
\text { deployment, mean (sd) }{ }^{* * *}\end{array}$ & $18.7(10.5)$ & $15.8(9.4)$ \\
\hline $\begin{array}{l}\text { Short dwell time between immediate prior } \\
\text { and index deployment }{ }^{\mathrm{b}}, n(\%)^{* *}\end{array}$ & $11,934(13.8)$ & $908(12.5)$ \\
\hline Any physical injury, military lifetime, $n(\%)^{* *}$ & $5,745(4.2)$ & $690(4.7)$ \\
\hline $\begin{array}{l}\text { Any mental health diagnoses, } \\
\text { military lifetime, } n(\%)^{* *}\end{array}$ & $17,660(12.8)$ & $3,835(26.2)$ \\
\hline $\begin{array}{l}\text { Any mental health treatment, } \\
\text { military lifetime, } n(\%)^{* * *}\end{array}$ & $15,118(11.0)$ & $2,647(18.1)$ \\
\hline
\end{tabular}

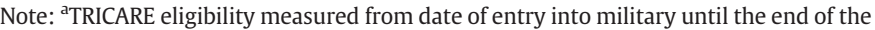

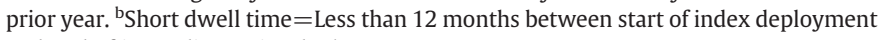
and end of immediate prior deployment.

Chi-square test for categorical variables. Wilcoxon rank-sum test for continuous variables.

*** $p<.0001 .{ }^{* *} p<.0005 . * p<.05$; p-value comparing men and women.
Table 2

Prior year substance use treatment in army men and women returning from deployment in FY2010, unadjusted.

\begin{tabular}{|c|c|c|c|c|}
\hline \multirow{2}{*}{$\begin{array}{l}\text { Substance Use Treatment } \\
\text { in the Prior Year }\end{array}$} & \multicolumn{2}{|c|}{ Men $n=137,814$} & \multicolumn{2}{|c|}{ Women $n=14,633$} \\
\hline & $\mathrm{N}(\%)$ & $(95 \% \mathrm{CI})$ & $\mathrm{N}(\%)$ & $(95 \% \mathrm{CI})$ \\
\hline Any SUT $^{\$}($ MDC 20$) * * *$ & $4,418(3.2)$ & $(3.1,3.3)$ & $309(2.1)$ & $(1.9,2.4)$ \\
\hline Any Inpatient SUT & $239(0.17)$ & $(0.15,0.20)$ & $28(0.19)$ & $(0.12,0.26)$ \\
\hline Any Outpatient Treatment*** & $4,364(3.2)$ & $(3.1,3.3)$ & $303(2.1)$ & $(1.8,2.3)$ \\
\hline
\end{tabular}

prevalence of men (12.8\%); and $18.1 \%$ of women had mental health treatment compared to $11.0 \%$ of men.

\subsection{Military lifetime substance use diagnoses}

Of the Army cohort returning in FY2010, 13.7\% received a SUDX in their military lifetime. In adjusted analyses, Army women $(12.0 \%$, $s d=4.6)$ were only slightly less likely than Army men $(13.9 \%$, $s d=4.8)$ to receive a military lifetime SUDX. In the multivariate model to determine military lifetime SUDX, female gender was associated with reduced odds of receiving a military lifetime SUDX (AOR 0.91, 95\% CI 0.86, 0.96), as well as black race (AOR 0.85, 95\% CI $0.81,0.89$ ) and being single (AOR $0.89,95 \% \mathrm{CI} 0.86,0.92$ ); and age was inversely associated with a military lifetime SUDX. Those who were commissioned (AOR $0.34,95 \%$ CI $0.32,0.36$ ) or warrant officers (AOR $0.44,95 \%$ CI $0.39,0.49$ ) had substantially lower odds than enlisted members. Prior deployment (AOR 1.18, 95\% CI 1.14, 1.23) and being widowed or divorced (AOR 1.15, 95\% CI 1.08, 1.23) were associated with increased odds. Short dwell time and months of TRICARE eligibility were included as control variables.

\subsection{Unadjusted prior year substance use treatment}

Table 2 reports the unadjusted prevalence of SUT utilization in the year prior to the index deployment. The observed prevalence of SUT utilization in the year prior to deployment was low for both Army women (2.1\%) and Army men (3.2\%). Less than one percent of Army men and women received inpatient SUT and the rate of receiving two or more outpatient SUT visits was $2.4 \%(\mathrm{n}=3,270)$ for men and $1.5 \%$ $(\mathrm{n}=214)$ for women.

\subsection{Adjusted prior year substance use treatment}

Table 3 reports the results of adjusted logistic regression and negative binomial models of the prior year SUT utilization dependent variables. These models control for variables representing predisposing, enabling, prior health behavior characteristics, and the propensity score for prior military lifetime SUDX which is a proxy measure for SUT need. Female gender was associated with 39\% lower odds of SUT utilization the year prior to deployment (AOR 0.61; 95\% CI 0.54, 0.70). Age was inversely associated and other variables associated with substantially reduced odds were commissioned (AOR 0.17, 95\% CI $0.12,0.23$ ) or warrant (AOR $0.29,95 \%$ CI $0.17,0.50$ ) officer rank, and prior deployment (AOR 0.89, 95\% CI 0.81, 0.98). Being Asian (AOR $1.19 ; 95 \% \mathrm{CI} 1.11,1.29$ ) or other race/ethnicity (AOR 1.18 ; $95 \% \mathrm{CI} 1.03$, 1.35) relative to white, being single (AOR 1.26; 95\% CI 1.14, 1.39), propensity for military lifetime SUDX (AOR 1.16, 95\% CI 1.06, 1.27), physical injury (AOR 1.63; 95\% CI 1.46, 1.83), and a history of military lifetime mental health treatment (AOR 2.12; 95\% CI 1.98, 2.27) were associated with higher odds of SUT in the year prior to deployment. We also controlled for short dwell time and months of TRICARE eligibility as a smaller exposure window may be confounded with other variables. In the multivariate model of number of outpatient 
Multivariate models coefficient estimates of prior year substance use treatment in army service members returning from deployment in FY2010.

\begin{tabular}{|c|c|c|c|c|}
\hline \multirow[b]{3}{*}{ Characteristics $\$$} & \multicolumn{4}{|c|}{ Dependent Variables } \\
\hline & \multicolumn{2}{|c|}{$\begin{array}{l}\text { Any SUT* } \\
(\mathrm{n}=152,447)\end{array}$} & \multicolumn{2}{|c|}{$\begin{array}{l}\text { \# Outpatient SUT Visits, given } \\
\text { treatment }+(\mathrm{n}=4,667)^{+}\end{array}$} \\
\hline & Odds Ratio & $95 \% \mathrm{CI}$ & Relative Risk & $95 \% \mathrm{CI}$ \\
\hline Gender (ref. male) & $0.61^{\text {*** }}$ & $0.54,0.70$ & 1.00 & $0.89,1.13$ \\
\hline Age, per year & $0.96^{* * *}$ & $0.95,0.98$ & $1.02^{* * *}$ & $1.01,1.03$ \\
\hline \multicolumn{5}{|l|}{ Race/ethnicity (ref. white) } \\
\hline Asian & $1.19^{* * *}$ & $1.11,1.29$ & 0.98 & $0.92,1.06$ \\
\hline Black & 1.04 & $0.94,1.16$ & 0.94 & $0.86,1.03$ \\
\hline Other & $1.18^{*}$ & $1.03,1.35$ & 1.00 & $0.87,1.13$ \\
\hline \multicolumn{5}{|l|}{ Marital Status (ref. married) } \\
\hline Single & $1.26^{* * *}$ & $1.14,1.39$ & 1.01 & $0.93,1.10$ \\
\hline Divorced/Widowed & 1.02 & $0.85,1.22$ & 0.91 & $0.77,1.07$ \\
\hline Single parent status & 1.13 & $0.99,1.31$ & 1.07 & $0.94,1.23$ \\
\hline \multicolumn{5}{|l|}{ Rank (ref. enlisted) } \\
\hline Officer & $0.17^{* * *}$ & $0.12,0.23$ & 0.92 & $0.69,1.23$ \\
\hline Warrant Officer & $0.29^{* * *}$ & $0.17,0.50$ & 0.80 & $0.49,1.29$ \\
\hline \# Military Dependents (per dependent) & $0.95^{* *}$ & $0.91,0.98$ & 0.98 & $0.95,1.01$ \\
\hline Months of TRICARE eligibility (per quartile) & $0.86^{*}$ & $0.78,0.95$ & 1.00 & $0.95,1.06$ \\
\hline Propensity score (per quintile) & $1.16^{*}$ & $1.06,1.27$ & 1.02 & $0.97,1.07$ \\
\hline Prior Deployment (ref. no) & $0.89^{*}$ & $0.81,0.98$ & 0.95 & $0.88,1.03$ \\
\hline Short dwell time & $0.70^{* * *}$ & $0.59,0.82$ & $0.74^{* * *}$ & $0.64,0.86$ \\
\hline Any physical injury (ref. no) & $1.63^{* * *}$ & $1.46,1.83$ & 0.98 & $0.88,1.09$ \\
\hline Any military lifetime MH treatment (ref. no) & $2.12^{* * *}$ & $1.98,2.27$ & $1.19^{* * *}$ & $1.12,1.27$ \\
\hline
\end{tabular}

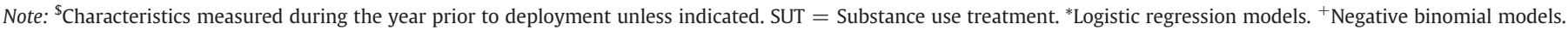
${ }^{* * * *} p<.0001 .{ }^{* *} p<.0005 .{ }^{*} p<.05 ; p$-value comparing men and women.

SUT visits, the rate for women did not differ from men (RR: $1.00 ; 95 \%$ CI: 0.89, 1.13).

\section{Discussion}

This is the first study examining gender differences in military lifetime SUDX and receipt of SUT the year prior to deployment in a cohort of Army service members. We present a novel approach to the study of gender disparity in SUT utilization by first estimating the likelihood of any military lifetime SUDX using propensity score modeling, and then estimating the relative likelihood of women receiving military-provided SUT in the year prior to deployment. In adjusted findings, $12 \%$ of Army women and $13.9 \%$ of Army men with a deployment ending in FY2010 had received a SUDX in their military lifetime. The definition of SUDX used in this study is based on receipt of a SUDX based on encounters at a military treatment facility or claims from a DoD-approved civilian treatment facility. This definition is conservative and may underestimate the true prevalence of $\mathrm{SU}$ problems in this Army cohort.

Army women were substantially less likely than Army men (AOR $0.61 ; 95 \%$ CI $0.54,0.70$ ) to receive SUT the year before deployment. Therefore, it is plausible that Army women may have more unmet SUT needs, which suggests gender disparities in access to SUT among active duty Army service members. This finding is consistent with prior studies involving civilian women (Weisner \& Schmidt, 1992) and women veterans seeking treatment in the VHA (Chatterjee et al., 2009; Hoff \& Rosenheck, 1997; Maynard et al., 2004). Civilian and VHA studies (Ashley et al., 2003; K. T. Brady \& Randall, 1999; T. M. Brady \& Ashley, 2005; Farmer, Rose, Riopelle, Lanto, \& Yano, 2011) consistently show that women may not receive SUT at the same rate as men, which is in part associated with women's higher rates of psychiatric diagnoses, their childcare needs, the confrontational nature of SUT, and gender differences in SU etiology, patterns, and disease progression.

In this study, Army women also had slightly lower prevalence of military SUDX than men, despite substantially different self-reported rates of SU problems in population-based studies of military service members (Bray \& Hourani, 2007; Bray et al., 2011). However, the prior year SUT rates for women were substantially lower than men, unlike the military lifetime SUDX rates. It is possible that some of the women with military lifetime SUDX in our study, relative to men, had lower severity of SU problems (see Brown et al., 2010; Jacobson et al., 2008; Stahre, Brewer, Fonseca, \& Naimi, 2009) and did not receive treatment in a military treatment facility.

Behaviors associated with SU problems may differ by gender. The Army's Substance Abuse Program (Department of the Army, 2009) is a commander's program that views SU problems and associated behaviors as a disciplinary problem that is inconsistent with good order and discipline in the military. As a result, Army service members are referred to SUT because of alcohol-related incidents (e.g., driving under the influence) and positive urinalysis test results for illicit drug use. Thus, if Army women who have SU problems are less likely than Army men to engage in externalizing behaviors associated with SU problems (e.g., aggression, physical injuries, or driving under the influence), they may be less likely to be referred to SUT. It is possible that Army women engaging in unhealthy drinking may have more internalizing behaviors than men (e.g., lethargy, flat affect, sleep) (Brown et al., 2010; Gutierrez et al., 2006), which may result in under-identified problem drinking and more disease progression before referral to SUT. Thus, Army women's untreated substance use could have a negative impact on their health and readiness by increasing their risk for training accidents, physical injuries, and over time, physical health problems. Other consequences of untreated SU problems prior to deployment may include more severe traumatic responses associated combat exposure, increased risk of military sexual trauma, and the exacerbation of post-deployment health problems. In the current operating environment, where all military leaders have a vested interest in maintaining the healthiest military force possible, it is prudent to investigate factors associated with the disproportionately lower prevalence of SUT utilization among Army women. More proactive military health policies regarding SU problem identification and treatment could benefit both military women and men.

Military leaders, health administrators, policymakers, and SUT professionals can play a vital role in the adoption of defense health policies that support the implementation of evidence-based SU assessment and treatment for Army women and men (Larson et al., 2012). Recent VHA research (Friedman et al., 2011; Oliva et al., 2012) 
provide examples of measures that may facilitate additional helpseeking among Army women, including organizational changes such as the availability of women's health services, specialized services for SUD patients with comorbid psychiatric disorders, and increasing the number of licensed psychosocial treatment providers. Future research including organizational and patient-level factors may assist in identifying strategies to increase help-seeking among Army women with SU problems.

The National Defense Authorization Act (110th Congress, 2008; 112th Congress, 2012) calls for the examination of the need for and efficacy of gender-specific behavioral health services. This study's findings provide preliminary evidence to support further exploration of gender disparities in SUT utilization in the military. Recent reports of the Institute of Medicine (Institute of Medicine, 2012) and Department of the Army (Department of the Army, 2010, 2012) describe the range of Army screening and treatment programs that could be evaluated to assess whether current protocols adequately identify SU problems in Army women and ensure they are as likely as men to be referred to treatment. For example, SU assessment, brief counseling, and primary care and mental health referral protocols could be reviewed to ensure that women and men's unique SU problem presentations are equally identified and treated. Study findings can also be a catalyst for future women's health research in other military services, such as the Air Force which has the largest proportion of military women and the Marine Corps which has the highest rate of heavy drinking (12.9\%) among military women (Ames \& Cunradi, 2004; Armed Forces Health Surveillance Center, 2011b).

There are several strengths and limitations of this study. Strengths include the examination of an understudied topic-gender differences in military-provided SUT, a large cohort of active duty Army service members returning from deployment, and use of an objective measure of SUT from health system data. Propensity score modeling is more robust to model misspecification than conventional regression and facilitates sensitivity analyses (Suarez \& Faries, 2010). Limitations include the retrospective observational study design resulting in unobserved differences in SUT among Army men and women for which we could not adjust. Furthermore, this study did not include measures of combat exposure, military sexual trauma, and command-directed or self-referral to SUT-all which may differ by gender. Another limitation is that this study only included patientlevel characteristics. Research on the Gelberg-Andersen Model (Gelberg et al., 2000) and VHA samples (Bean-Mayberry et al., 2007; Oishi et al., 2011; Oliva et al., 2012; Washington, BeanMayberry, Mitchell, Riopelle, \& Yano, 2011) all suggest organizationallevel factors can be barriers and facilitators to care with plausibly different outcomes for women and men.

$\mathrm{SU}$ is a growing public health problem among OEF/OIF veterans that may negatively impact military health and readiness. Examining SUT utilization in OEF/OIF veterans is critical to planning for the current and future health care needs of recently returned veterans, the infrastructure and workforce capabilities of the MHS, and the development of defense health policies that ensure military men and women with SU problems have equal access to SUT. This study found gender disparities in military lifetime SUDX and SUT utilization the year prior to deployment in OEF/OIF veterans. However, questions remain about the factors that led to our study findings. Disparate SUT rates may be the result of differential access to care or a lack of gender-sensitive assessment and treatment protocols. Because active duty Army women receive free healthcare in the MHS and the civilian SUT system may not adequately address the unique needs of military personnel (National Association of State Alcohol and Drug Abuse Directors, 2009), the best opportunity for Army women to access quality SUT services would occur if the MHS adopted evidence-based, gender-sensitive SUT programs. Undoubtedly, unaddressed SUT needs prior to deployment may be associated with the postdeployment health care needs of returning veterans. Given SUT has demonstrated effectiveness in reducing the SU problems of both men and women (Greenfield, Pettinati, O'Malley, Randall, \& Randall, 2010; Greenfield et al., 2007; Marsh et al., 2009), the MHS should continue to examine how it can best meet the SUT needs of Army women whose behavioral health status can impact the health and readiness of the armed forces.

\section{Acknowledgments}

This study was funded by the National Institute of Drug Abuse (NIDA; \#R01DA030150, PI: Dr. Larson). Dr. Wooten acknowledges support from a NIDA Diversity Supplement (\#R01DA030150-S1). The Office of the Assistant Secretary of Defense for Health Affairs/TRICARE Management Activity of the United States Department of Defense (DoD) provided access to these data. The opinions and assertions herein are those of the authors and do not necessarily reflect the view of the DoD. This research has been conducted in compliance with all applicable federal regulations governing the protection of human subjects. Drs. Thomas V. Williams and Diana D. Jeffery were the TMA/ DoD Government Project Managers who sponsored access to the DoD data sources.

\section{References}

Adams, R. S., Larson, M. J., Corrigan, J. D., Horgan, C. M., \& Williams, T. V. (2012). Frequent binge drinking after combat-acquired traumatic brain injury among active duty military personnel with a past year combat deployment. The Journal of Head Trauma Rehabilitation, 27, 349-360.

Aday, L., \& Andersen, R. (1974). A framework for the study of access to medical care. Health Services Research, 9, 208-220.

Aday, L., \& Awe, W. (1997). Health services utilization models. In D. Gochman (Ed.), Handbook of health behavior research I: Personal and social determinants (pp. 153-172). New York: Plenum Press.

Ames, G., \& Cunradi, C. (2004). Alcohol use and preventing alcohol-related problems among young adults in the military. Alcohol Research \& Health, 28, 252-257.

Andersen, R. (1995). Revisiting the behavioral model and access to medical care: Does it matter? Journal of Health and Social Behavior, 36, 1-10.

Armed Forces Health Surveillance Center (2010). Childbirth, deployment, and diagnoses of mental disorders among active component women, January 2002june 2009. Medical Surveillence Monthly Report, 17, 17-21.

Armed Forces Health Surveillance Center (2011a). Alcohol-related diagnoses, active component, US Armed Forces, 2001-2010. Medical Surveillance Monthly Report, 18, 9-13.

Armed Forces Health Surveillance Center (2011b). Numbers and characteristics of women in the active component, US Armed Forces, 2011. Medical Surveillance Monthly Report, 18, 18-19.

Armed Forces Health Surveillance Center (2012a). Health of women after wartime deployments: correlates of risk for selected medical conditions among females after initial and repeat deployment to Afghanistan and Iraq, active component, US Armed Forces. Medical Surveillance Monthly Report, 19, 2-10.

Armed Forces Health Surveillance Center (2012b). Medical evacuation from operation Iraqi freedom/operation new dawn, active and reserve components, US Armed Forces, 2003-2011. Medical Surveillance Monthly Report, 19, 18-21.

Ashley, O. S., Marsden, M. E., \& Brady, T. M. (2003). Effectiveness of substance abuse treatment programming for women: A review. The American Journal of Drug and Alcohol Abuse, 29, 19-53.

Bean-Mayberry, B., Yano, E. M., Bayliss, N. Navratil, J., Weisman, C. S. \& Scholle, S. H. (2007). Federally funded comprehensive women's health centers: Leading innovation in women's healthcare delivery. Journal of Women's Health, 16(9), 1281-1290, http://dx.doi.org/10.1089/jwh.2006.0284.

Brady, K. T., \& Randall, C. L. (1999). Gender differences in substance use disorders. Psychiatric Clinics of North America, 22, 241-252.

Brady, T. M., \& Ashley, O. S. (2005). Women in substance abuse treatment: Results from the Alcohol and Drug Services Study (ADSS). Rockville, MD: Substance Abuse and Mental Health Services Administration, Office of Applied Studies.

Bray, R., \& Hourani, L. L. (2007). Substance use trends among active duty military personnel: Findings from the United States Department of Defense Health Related Behavior Surveys, 1980-2005. Addiction, 102, 1092-1101.

Bray, R., Hourani, L. L., \& Williams, J. (2011). Substance use and mental health risk factors for service members: Findings from US Department of Defense Health Related Behavior Surveys. Paper presented at the NATO Conference on Mental Health and Well-Being Across the Military Spectrum. Norway: Bergen.

Bray, R., Pemberton, M. R., Hourani, L. L., Witt, M., Olmsted, K. L. R., Brown, J. M., et al. (2009). 2008 Department of Defense Survey of Health Related Behaviors among active duty military personnel. (RTI/10940-FR). Research Triangle Park: RTI International.

Brown, J. M., Bray, R. M., \& Hartzell, M. C. (2010). A comparison of alcohol use and related problems among women and men in the military. Military Medicine, 175, 101-107. 
Chatterjee, S., Rath, M. E., Spiro, A., III, Eisen, S., Sloan, K. L., \& Rosen, A. K. (2009). Gender differences in Veterans Health Administration mental health service use: Effects of age and psychiatric diagnosis. Women's Health Issues, 19, 176-184.

Cobb Scott, J., Pietrzak, R. H., Mattocks, K., Southwick, S. M., Brandt, C., \& Haskell, S. (2012). Gender differences in the correlates of hazardous drinking among Iraq and Afghanistan veterans. Drug and Alcohol Dependence doi: http://dx.doi.org/10.1016/ j.drugalcdep.2012.06.003.

110th Congress (2008). National Defense Authorization Act for Fiscal Year 2008. PL $110-181, \S 716$.

112th Congress (2012). National Defense Authorization Act for Fiscal Year 2008. HR $1540, \S 725,1$ st Stat. 565

Davis, T. M., \& Wood, P. S. (1999). Substance abuse and sexual trauma in a female veteran population. Journal of Substance Abuse Treatment, 16(2), 123-127.

Department of the Army (2009). Army substance abuse program. (AR 600-85). Washington, DC: Headquarters, Department of the Army.

Department of the Army (2010). Army health promotion, risk reduction, suicide prevention report. Washington, DC: Headquarters, Department of the Army.

Department of the Army (2012). Army 2020: Generating health and discipline in the force: Ahead of the strategic reset. Washington, DC: Headquarters, Department of the Army.

Edens, E. L., Kasprow, W., Tsai, J., \& Rosenheck, R. (2011). Association of substance use and VA service-connected disability benefits with risk of homelessness among veterans. The American Journal on Addictions, 20, 412-419.

Farmer, M. M., Rose, D. E., Riopelle, D., Lanto, A. B., \& Yano, E. M. (2011). Gender differences in smoking and smoking cessation treatment: An examination of the organizational features related to care. Women's Health Issues, 21(4 Supplement), S182-S189, http://dx.doi.org/10.1016/j.whi.2011.04.018.

Federman, E. B., Bray, R. M., \& Kroutil, L. A. (2000). Relationships between substance use and recent deployments among women and men in the military. Military Psychology, 12, 205-220.

Friedman, S. A., Phibbs, C. S., Schmitt, S. K., Hayes, P. M., Herrera, L., \& Frayne, S. M. (2011). New women veterans in the VHA: A longitudinal profile. Women's Health Issues, 21, S103-S111, http://dx.doi.org/10.1016/j.whi.2011.04.025.

Gelberg, L., Andersen, R., \& Leake, B. (2000). The behavioral model for vulnerable populations: Application to medical care use and outcomes for homeless people. Health Services Research, 34, 1273-1302.

Gibbons, S. W., Barnett, S. D., Hickling, E. J., Herbig-Wall, P. L., \& Watts, D. D. (2012). Stress, coping, and mental health-seeking behaviors: Gender differences in oef/oif health care providers. Journal of Traumatic Stress, 25, 115-119, http:// dx.doi.org/10.1002/jts.21661.

Greenfield, S., Brooks, A. J., Gordon, S. M., Green, C. A., Kropp, F., McHugh, R. K., et al. (2007). Substance abuse treatment entry, retention, and outcome in women: A review of the literature. Drug and Alcohol Dependence, 86, 1-21.

Greenfield, S., Pettinati, H., O'Malley, S., Randall, P., \& Randall, C. L. (2010). Gender differences in alcohol treatment: An analysis of outcome from the combine study Alcohol Clinical \&' Experimental Research, 34, 1803-1812.

Grella, C. E., Greenwell, L., Mays, V. M., \& Cochran, S. D. (2009). Influence of gender, sexual orientation, and need on treatment utilization for substance use and mental disorders: Findings from the California Quality of Life Survey. BMC Psychiatry, 9(1), 52-61.

Gutierrez, C. A., Blume, A. W., Schmaling, K. B., Stoever, C. J., Fonseca, C., \& Russell, M. L. (2006). Predictors of aversive alcohol consequences in a military sample. Military Medicine, 171, 870-874.

Harris, A. H., Bowe, T., Finney, J. W., \& Humphreys, K. (2009). HEDIS initiation and engagement quality measures of substance use disorder care: Impact of setting and health care specialty. Population Health Management, 12(4), 191-196, http:// dx.doi.org/10.1089/pop.2008.0028.

Hoff, R. A., \& Rosenheck, R. A. (1997). Utilization of mental health services by women in a male-dominated environment: The VA experience. Psychiatric Services, 48 1408-1414.

Hoge, C., Castro, C. A., Messer, S. C., McGurk, D., Cotting, D. I., \& Koffman, R. L. (2004). Combat duty in Iraq and Afghanistan, mental health problems, and barriers to care. New England Journal of Medicine, 351, 13-22, http://dx.doi.org/10.1056/ NEJMoa040603351/1/13.

Hoge, C., Toboni, H. E., Messer, S. C., Bell, N., Amoroso, P., \& Orman, D. T. (2005). The occupational burden of mental disorders in the U.S. Military: Psychiatric hospitalizations, involuntary separations, and disability. American Journal of Psychiatry, 162, 585-591, http://dx.doi.org/10.1176/appi.ajp.162.3.585.

Institute of Medicine. (2012). Substance use disorders in the U.S. Armed forces Washington, DC: The National Academies Press. Institute of Medicine.

Jacobson, I. G., Ryan, M. A., Hooper, T. I., Smith, T. C., Amoroso, P. J., Boyko, E. J., et al. (2008). Alcohol use and alcohol-related problems before and after military combat deployment. Journal of the American Medical Association, 300, 663-675 doi 300/6/663 [pii]10.1001/jama.300.6.663.

Kelty, R., Kleykamp, M., \& Segal, D. R. (2010). The military and the transition to adulthood. The Future of Children, 20, 181-207.

Larson, M. J., Wooten, N. R., Adams, R. S., \& Merrick, E. L. (2012). Military combat deployments and substance use: Review and future directions. Journal of Social Work Practice in the Addictions, 12(1), 6-27 PMCID: PMC3321386.

Lindstrom, K. E., Smith, T. C., Wells, T. S., Wang, L. Z., Smith, B., Reed, R. J., et al. (2006). The mental health of us military women in combat support occupations. Journal of Women's Health, 15, 162-172.

Lundgren, L. M., Amodeo, M., Ferguson, F., \& Davis, K. (2001). Racial and ethnic differences in drug treatment entry of injection drug users in Massachusetts. Journal of Substance Abuse Treatment, 21, 145-153.
Lundren, L.M., Brännström, J., Chassler, D., Wilkey, C., Sullivan, L., \& Nordström, A. (in press). Mental health, substance use, and criminal justice characteristics of males with a history of abuse in a Swedish national sample. Journal of Dual Diagnosis.

Manning, L., \& Wight, V. R. (2000). Women in the military: Where they stand (3rd ed.) Washington, DC: Women's Research \& Education Institute.

Marsh, J., Cao, D., \& Shin, H. (2009). Closing the need-service gap: Gender differences in matching services to client needs in comprehensive substance abuse treatment. Social Work Research, 33, 183-192.

Maynard, C., Kivlahan, D. R., Sloan, K. L., Krupski, A., Saxon, A. J., \& Stark, K. (2004). Use of Veterans Affairs health care services by veterans receiving addiction treatment in Washington state. Psychological Services, 1, 120-125.

National Association of State Alcohol and Drug Abuse Directors (2009). Addressing the substance use disorder service needs of returning veterans and their families: The training needs of state alcohol and other drug agencies and providers. Washington, DC: Substance Abuse and Mental Health Services Administration, Center for Substance Abuse Treatment.

Nazarian, D., Kimerling, R., \& Frayne, S. M. (2012). Posttraumatic stress disorder substance use disorders, and medical comorbidity among returning us veterans. Journal of Traumatic Stress, 25, 220-225.

Obot, I. S., \& Room, R. (Eds.). (2005). Alcohol, gender, and drinking problems: Perspectives from low and middle income countries. Geneva, Switzerland: Department of Mental Health and Substance Abuse, World Health Organization.

Oishi, S. M., Rose, D. E., Washington, D. L., MacGregor, C., Bean-Mayberry, B., \& Yano, E. M. (2011). National variations in VA mental health care for women veterans. Women's Health Issues, 21(4, Supplement), S130-S137, http://dx.doi.org/10.1016/ j.whi.2011.04.029.

Oliva, E. M., Gregor, A., Rogers, J., Dalton, A., Harris, A. H. S., \& Trafton, J. A. (2012), Correlates of specialty substance use disorder treatment among female patients in the Veterans Health Administration. Journal of Social Work Practice in the Addictions, 12, 282-301, http://dx.doi.org/10.1080/1533256x.2012.702620.

Petrakis, I. L., Rosenheck, R., \& Desai, R. (2011). Substance use comorbidity among veterans with posttraumatic stress disorder and other psychiatric illness. The American Journal on Addictions, 185-189.

Ramchand, R., Miles, J., Schell, T., Jaycox, L., Marchall, G. N., \& Tanielian, T. (2011). Prevalence and correlates of drinking behaviors among previously deployed military and matched civilian populations. Military Psychology, 23, 6-21.

Institute Incorporated, S. A. S. (2008). SAS for windows 9.2. Cary, NC: SAS Institute Inc.

Saum, C. A., Hiller, M. L., Leigey, M. E., Inciardi, J. A., \& Surratt, H. L. (2007). Predictors of substance abuse treatment entry for crime-involved, cocaine-dependent women. Drug and Alcohol Dependence, 91(2), 253-259.

Schmidt, L., Tam, T., \& Larson, M. J. (2012). Sources of biased inference in alcohol and drug services research: An instrumental variable approach. Journal of Studies on Alcohol and Drugs, 73, 144-153.

Scioli, E., Otis, J., \& Keane, T. (2010). Psychological problems associated with Operation Enduring Freedom/Operation Iraqi Freedom deployment. American Journal of Lifestyle Medicine, 4, 349-359.

Seal, K. H., Bertenthal, D., Miner, C. R., Sen, S., \& Marmar, C. (2007). Bringing the war back home: Mental health disorders among 103,788 US veterans returning from Iraq and Afghanistan seen at Department of Veterans Affairs facilities. Archives of Internal Medicine, 167, 476-482 doi: 167/5/476 [pii] 10.1001/archinte.167.5.476.

Shen, Y. -C., Arkes, J., \& Williams, T. V. (2012). Effects of Iraq/Afghanistan deployments on major depression and substance use disorder: Analysis of active duty personnel in the US military. American Journal of Public Health, 102(S1), S80-S87.

Skinner, K. M., Kressin, N., Frayne, S., Tripp, T. J., Hankin, C. S., Miller, D. R., et al. (2000). The prevalence of military sexual assault among female Veterans' administration outpatients. Journal of Interpersonal Violence, 15(3), 291-310.

Smith, T., Jacobson, I. G., Smith, B., Hooper, T. I., Ryan, M. A. K., Team, F., et al. (2007a). The occupational role of women in military service: Validation of occupation and prevalence of exposures in the millennium cohort study. International Journal of Environmental Health Research, 17, 271-284.

Smith, T., Zamorski, M., Smith, B., Riddle, J., LeardMann, C., Wells, T., et al. (2007b). The physical and mental health of a large military cohort: Baseline functional health status of the Millennium Cohort. BMC Public Health, 7, 340.

Stahre, M. A., Brewer, R. D., Fonseca, V. P., \& Naimi, T. S. (2009). Binge drinking among US active-duty military personnel. American Journal of Preventive Medicine, 36(3), 208-217.

Stecker, T., Fortney, J., Owen, R., McGovern, M. P., \& Williams, S. (2010). Co-occurring medical, psychiatric, and alcohol-related disorders among veterans returning from Iraq and Afghanistan. Psychosomatics, 51, 503-507, http://dx.doi.org/10.1176/ appi.psy.51.6.503.

Stein, J. A., Andersen, R. M., Robertson, M., \& Gelberg, L. (2012). Impact of hepatitis b and $\mathrm{c}$ infection on health services utilization in homeless adults: A test of the GelbergAndersen behavioral model for vulnerable populations. Health Psychology, 31(1), 20-30.

Street, A. E., Vogt, D., \& Dutra, L. (2009). A new generation of women veterans: Stressors faced by women deployed to Iraq and Afghanistan. Clinical Psychology Review, 29 685-694.

Suarez, D., \& Faries, D. E. (2010). Propensity score stratification and regression. In D. E. Faries, A. C. Leon, J. M. Haro, \& R. L. Obenchain (Eds.), Analysis of observational health care data using SAS. (pp. 23-49). Cary, NC: SAS Institute Inc.

Suris, A., \& Lind, L. (2008). Military sexual trauma a review of prevalence and associated health consequences in veterans. Trauma, Violence E' Abuse, 9, 250-269.

Surís, A., Lind, L., Kashner, T. M., Borman, P. D., \& Petty, F. (2004). Sexual assault in women veterans: An examination of PTSD risk, health care utilization, and cost of care. Psychosomatic Medicine, 66(5), 749-756, http://dx.doi.org/10.1097/01. psy.0000138117.58559.7b. 
Tucker, J. S., Wenzel, S. L., Golinelli, D., Zhou, A., \& Green, H. D. (2011). Predictors of substance abuse treatment need and receipt among homeless women. Journal of Substance Abuse Treatment, 40(3), 287-294.

Vijayaraghavan, M., Tochterman, A., Hsu, E., Johnson, K., Marcus, S., \& Caton, C. L. (2012). Health, access to health care, and health care use among homeless women with a history of intimate partner violence. Journal of Community Health, 1-8.

Vogt, D., Vaughn, R., Glickman, M., Schultz, M., Drainoni, M., Elwy, R., et al. (2011). Gender differences in combat-related stressors and their association with postdeployment mental health in a nationally representative sample of U.S. OEF/OIF veterans. Journal of Abnormal Psychology, 120, 797-806, http://dx.doi.org/ 10.1037/a002345210.1037/a0023452.supp (Supplemental).
Wallace, A. E., Sheehan, E. P., \& Young-Xu, Y. (2009). Women, alcohol, and the military: Cultural changes and reductions in later alcohol problems among female veterans. Journal of Women's Health, 18, 1347-1353, http://dx.doi.org/10.1089/ jwh.2008.0861.

Washington, D. L., Bean-Mayberry, B., Mitchell, M. N., Riopelle, D., \& Yano, E. M. (2011) Tailoring VA primary care to women veterans: Association with patient-rated quality and satisfaction. Women's Health Issues, 21(4, Supplement), S112-S119, http://dx.doi.org/10.1016/j.whi.2011.04.004.

Weisner, C., \& Schmidt, L. (1992). Gender disparities in treatment for alcohol problems Journal of the American Medical Association, 268, 1872-1876, http:// dx.doi.org/10.1001/jama.1992.03490140080039. 